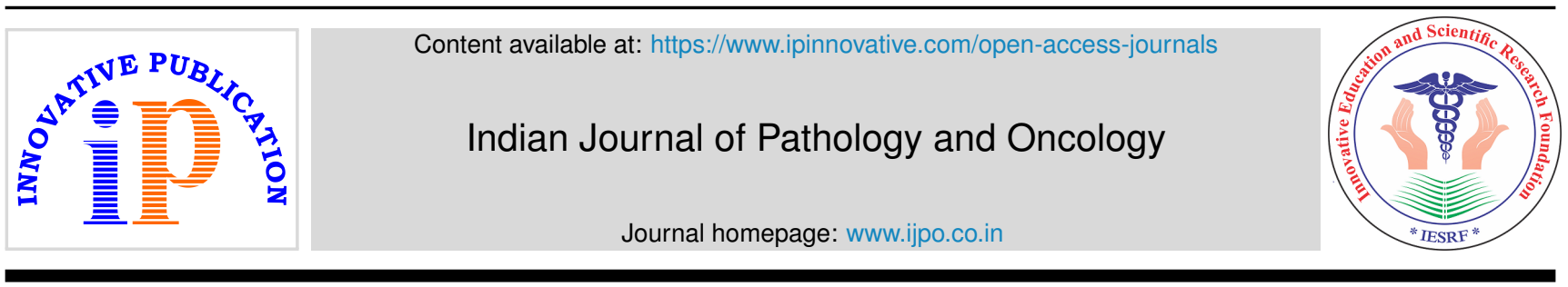

Original Research Article

\title{
A histo-pathological study with an emphasis on stratification of pigmented lesions of the skin
}

\author{
Ishant Anand $^{1}$, Sandhya Ilanthodi ${ }^{1}{ }^{*}$, Girish P N, Muktha R Pai ${ }^{1}$ \\ ${ }^{1}$ Dept. of Pathology, AJ Institute of Medical Sciences, Mangalore, Karnataka, India
}

\section{A R T I C L E I N F O}

\section{Article history:}

Received 11-06-2020

Accepted 14-08-2020

Available online 19-11-2020

\section{Keywords:}

Melanoma

Naevi

Seborrhoeic keratosis

Basal cell carcinoma

\begin{abstract}
A B S T R A C T
Background: Pigmented lesions can be close mimickers of melanoma and clinically challenging to diagnose. These can be melanocytic or non-melanocytic pigmented disorders. Pigmented lesions are close mimickers of melanoma and histopathology is a cornerstone for diagnosing these lesions.

Aims and Objectives: 1 . To study the histomorphological patterns of pigmented lesions of the skin; 2 . To categorise and differentiate pigmented lesions from melanoma based on histomorphology.

Settings and Design: A total of 70 histologically diagnosed cases of pigmented lesions of the skin were retrospectively studied from January 2018 to December 2019 in department of Pathology, of a Tertiary care center, Mangalore (India).

Materials and Methods: Clinically suspicious skin lesions were taken up for the study. Sections from the skin punch biopsies and wide excision of the lesion were processed, stained with Hematoxylin and Eosin stain and studied for its histomorphological features.

Results: Out of the 70 cases studied, 22 cases were melanocytic lesions including 12 cases of Malignant melanoma (17.1\%), Benign Naevi- 10 cases (14.2\%) and 48 cases were non-melanocytic lesions including Lichen planus- 30 cases (42\%), Seborrheic keratosis- 10 cases (14.3\%), Basal cell carcinoma- 8 cases $(11.4 \%)$.

Conclusion: The pigmented lesions are categorised into melanocytic and non melanocytic lesions for a better understanding. Among the Melanocytic lesions, our study witnessed predominantly cutaneous melanoma. And in non melanocytic lesions lichen planus predominated.

(C) This is an open access article distributed under the terms of the Creative Commons Attribution License (https://creativecommons.org/licenses/by/4.0/) which permits unrestricted use, distribution, and reproduction in any medium, provided the original author and source are credited.
\end{abstract}

\section{Introduction}

Pigmented lesions of the skin are of cosmetic as well as diagnostic concern. It refers to an increase in melanin pigment in the epidermis or dermis. This can be due to inflammation, proliferation of basal cells in the epidermis and proliferation of melanocytes. "Increase in melanin pigment or melanocytic proliferation can either be in the epidermis which is characterized by 'Brown hyperpigmentation' and dermis which is known as 'blue hyperpigmentation' or 'Ceruloderma." 'Melanocytic lesions include benign naevi and malignant melanoma. Benign melanocytic lesions are called Melanocytic naevi

\footnotetext{
* Corresponding author.

E-mail address: drsandhyai@yahoo.co.in (S. Ilanthodi).
}

whereas malignant lesions of the melanocytes are malignant melanomas. These can be close mimickers and clinically challenging to diagnose.

Specific differences between Melanocytes and Nevus cells histomorphologically are given in Table 1 :

Table 1: Histomorphological differences between Melanocytes and Nevus cells

\begin{tabular}{ll}
\hline Melanocytes & Nevus Cells \\
Contour is dendritic & $\begin{array}{l}\text { Contour is rounded or } \\
\text { spindle-shaped } \\
\text { Cells are arranged in clusters }\end{array}$ \\
Cells are solitary & $\begin{array}{l}\text { Nuclei of most cells are small } \\
\text { and regular } \\
\text { Nuclei are small and regular } \\
\text { Mitoses are very rare }\end{array}$ \\
\hline
\end{tabular}


"Melanocytic lesions are important as malignant melanoma which accounts for only $1 \%$ of skin cancers, is responsible for over $60 \%$ of cancer related deaths." 2 Nonmelanocytic lesions include lesions such as lichen planus, seborrheic keratosis, pigmented basal cell carcinoma etc.

Melanocytic nevi: "Melanocytic nevi present mostly in adolescence. These naevi are believed to start as junctional nevi, progressing to compound nevi and having become intradermal nevi.",3

Malignant melanoma: "Hippocrates first described cutaneous malignant melanoma as "black cancer". The word Melanoma was coined by Rene Laennec. He first described the disease in 1806." 4 The peak incidence is around the sixth decade of life. Head and neck are the most common site of distribution of the disease because of its association with exposure to sunlight in western countries. However, in India, although rare, it occurs in the extremities and does not have association with sunlight exposure. In this study, among cutaneous melanoma, the lower extremity was the most common site, which was in accordance with the previous studies by "Radhika et al." 5 and "Tjarta et al." 6 Literature says, lower extremities are the most common site of involvement in males, while the trunk is the most common site in females. However, in western studies, "maximum cases are observed in lower extremities such as the sole of foot in both sexes." 7

"In India and other Asian studies, acral lentiginous type was the most common type of Malignant Melanoma. While in Western studies, majority were superficial spreading melanoma." 8-11 However, "in an Indian study, superficial melanoma was the most common followed by acral lentigo", 2 and contrarily the present study, shows acral lentiginous melanoma as the most common (59.4\%) Malignant melanoma followed by superficial melanoma.

Table 2: List of pigmented lesions of the skin

\begin{tabular}{lc}
\hline Pigmented Lesions & Percentage of cases \\
Melanoma & $8 \%$ \\
Dysplastic Naevus & $64 \%$ \\
Congenital Naevus & $11 \%$ \\
Blue Naevus & $1 \%$ \\
Spitz Naevus & $1 \%$ \\
Pigmented Squamous cell carcinoma & $0.6 \%$ \\
Basal cell carcinoma & $1.4 \%$ \\
Seborrheic Keratosis & $7 \%$ \\
Actinic Keratosis & $1 \%$ \\
Lentigo & $5 \%$ \\
\hline
\end{tabular}

\section{Materials and Methods}

This is a retrospective study undertaken by the department of Pathology in patients of all age groups clinically diagnosed with pigmented skin lesions from January 2018 to December 2019. Variables like age, gender of the patient, site of the lesion and histomorphological features were retrieved from the archives of the Department of Pathology.

The study intended to include clinically diagnosed pigmented lesions of the skin. Skin punch biopsies were performed on small lesions, and on larger lesions excision biopsy was done.

For histopathology processing, biopsy tissues were routinely fixed in $10 \%$ formalin. The sections were cut and stained using routine hematoxylin and eosin stain. Biopsies were studied and detailed examinations of epidermal and dermal features were done.

\subsection{Inclusion criteria}

All the neoplastic and non-neoplastic pigmented lesions of the skin from all age groups and both genders were included in the study.

\subsection{Exclusion criteria}

Inadequate biopsy specimen and skin biopsies other than pigmented lesions were excluded from the study.

\section{Results}

Out of the 70 cases studied, 22(31\%) cases are melanocytic lesions including Malignant melanoma- 12 cases(17.1\%), Benign Naevi- 10 cases(14.2\%) and 48(69\%) cases are non-melanocytic lesions including Lichen planus- 30 cases(42\%), Seborrheic keratosis-10 cases(14.3\%), Basal cell carcinoma- 8 cases $(11.4 \%)$. [Figure 1]

These cases are distributed in the age group of 8 years to 92 years. Although the distribution of these lesions overall are equal in both males and females, this distribution started showing a pattern when these lesions were studied individually. Male to Female ratio in these lesions show a male preponderance in Malignant melanoma 11:1, Seborrhoeic keratosis 7:3, Basal cell carcinoma 5:3 and lesions more common in females were Lichen planus 1:2 and Benign Naevi 1:9.

The most common site of distribution of pigmented lesions of the skin are extremities more than head and neck and trunk. $70 \%$ of benign naevi cases are in the head and neck region, $100 \%$ cases of malignant melanoma cases are in extremities, again $70 \%$ of Seborrhoeic keratosis cases are in the head and neck region. $100 \%$ of the Basal cell carcinoma cases are in the face, head and neck area and lichen planus occurs most commonly in the extremities.

Among melanocytic lesions, malignant melanomas are the most common lesions $(17.1 \%)$. Maximum number of cases are in the age group of 50-70 year old.(66.6\%) Melanomas arise in the epidermis, it can be in-situ or invasive into the dermis.

In our study out of 12 cases, 3 cases are Nodular type, 4 cases are Acral lentiginous type, 3 are NOS, 1 case of Nevoid melanoma and 1 case of cutaneous 
myxoid melanoma studied. Histomorphological features are emphasized in [Table 3].

The tumour cells are predominantly epithelioid to spindle cell type. Other features present are hyperparakeratosis and ulcerations. Clarks grading was done and majority (41.6\%) of the lesions are of Grade V. [Table 3]

Benign naevus also known as birthmarks are congenital or acquired benign melanocytic proliferations. Presence of naevi cells along with other features like hyperkeratosis, parakeratosis and acanthosis are noted in our study. Few nests of naevi cells show melanin pigments. Out of 22 pigmented melanocytic lesions 10 cases are Benign naevi.

Intradermal naevi is the most common type in the current study, other types being Epidermolytic verrucous epidermal naevi, Compound naevi, halo nevus, Cellular blue naevi and Naevus sebaceous of Jadasshon.

Characteristic features of these Naevi studied showsymmetrical, small and well circumscribed lesions. Melanocytes decrease in size as they go deeper into the dermis. Mitotic activity is absent at the base of the lesion. [Table 3]

1. Intradermal naevus: It typically appears as an elevated, dome-shaped bump on the surface of the skin. Naevi cells are predominantly present in the dermis. [Figure 6]

2. Cellular blue naevus: Heavy infiltration of melanin pigments and non-nested dermal infiltration of naevus cells with associated fibrosis.

3. Compound naevus: Shows nests and cords of nevus cells in the intraepidermal and underlying dermis.

4. Halo naevus: Lymphocytic infiltration around the naevus cells. [Figure 8]

In the present study there are a total of $8(11.5 \%)$ cases of BCC. Studies show BCC as the most common malignancy of the skin, constituting $\sim 80 \%$ of all skin cancers and yet in our study malignant melanoma predominates over BCC. Multiple BCCs develop early in life in patients with Basal cell nevus syndrome(Gorlin- Goltz syndrome).

A case of Gorlin-Goltz syndrome is included in the study. Patient presented with Odontogenic Keratocyst, extensive calcification in the Falx Cerebri, Tentorium and Falx Cerebelli, with multiple pigmented plaques in the trunk, back, bilateral upper limbs and face. These lesions were biopsied. Histologically lesions showed solid groups of atypical basaloid cells at the dermo-epidermal junction showing peripheral palisading. Other features like the artifactual spaces between the tumour and the dermis directs towards the diagnosis of Nevoid Basal cell Carcinoma syndrome (Gorlin-Goltz syndrome) [Figure 7]

In overall distribution of pigmented lesions of the skin, lichen planus was the most common type of lesion seen in our study i.e. $42 \%$ (30 cases). Histomorphological features studied were wedge shaped hypergranulosis, basal cell vacuolization, band like infiltration, civatte bodies and colloid bodies. 2 of the cases also showed Max Joseph spaces. Pigment incontinence was noted, contributing to the skin pigmentation in the lesions. [Figure 3]

Out of 10 cases of Seborrheic keratosis studied, Acanthotic type of Seborrhoeic keratosis were the most common type. Histologically these lesions showed hyperkeratosis,papillomatosis, acanthosis with proliferating basaloid cells, presence of horn cysts [Figure 4]. Dermis showed perivascular inflammation. The Remaining three cases were of hyperkeratotic type.

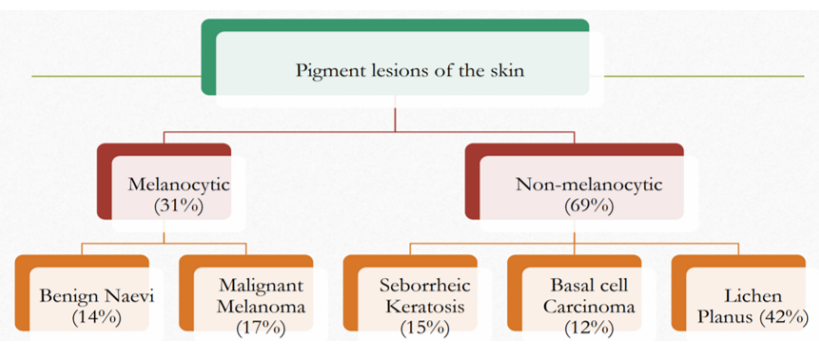

Fig. 1: Distribution of pigmented lesions of the skin

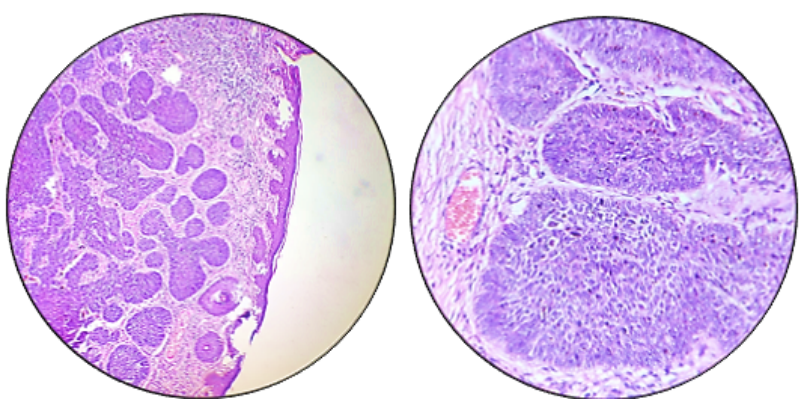

Fig. 2: BCC

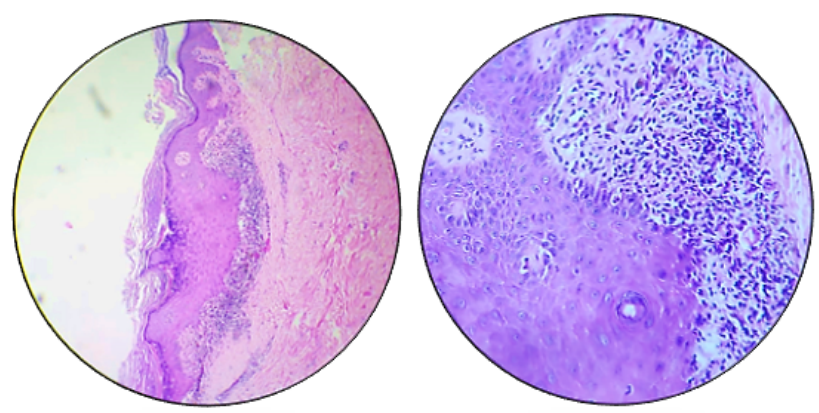

Fig. 3: Lichen planus

\section{Discussion}

Pigmented lesions contribute a significant number of lesions biopsied for various reasons, but of primary concern is 
Table 3: Most common histomorphological features in the lesions studied:

\section{Benign Naevi}

Hyperkeratosis

Parakeratosis

Acanthosis

Naevi cells +

Types(most common)Intradermal Naevi

Other types-

Compound naevi

Melanoctyic naevi

Naevus sebaceous of Jadassohn

Epidermolytic veruccous epidermal naevi

\section{Malignant Melanoma}

Hyperkeratosis

Parakeratosis

Acanthosis

Tumour cell type-

Epithelioid to spindle shaped

Clark's grading (most common)- Grade V

Nodular type

Acral lentiginous type NOS

Nevoid melanoma

Cutaneous myxoid melanoma

$\begin{array}{ll}\text { Seborrhoeic Keratosis } & \text { Basal cell Carcinoma } \\ \text { Hyperkeratosis } & \text { Peripheral palisading } \\ \text { Parakeratosis } & \text { Retraction artefact } \\ \text { Acanthosis } & \text { Cystic change } \\ \text { Orthokeratosis } & \text { Inflammation }\end{array}$

Horn cysts +

Lymphocytic infiltrate
Lichen Planus

Hyperkeratosis

Orthokeratosis

Hypergranulosis

Acanthosis

Basaloid cells

Basal cell vacuolation

Type(most common)-

Nodular

\section{Band like infiltration}

$\begin{array}{ll}\text { Basaloid proliferation } & \begin{array}{l}\text { Other type- } \\ \text { Gorlin-Goltz Syndrome }\end{array}\end{array}$
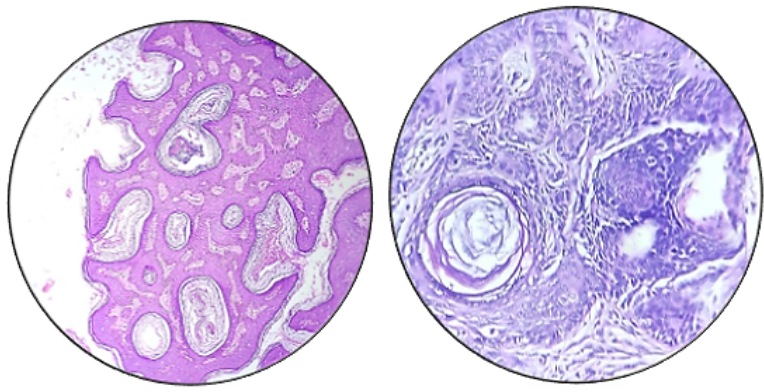

Fig. 4: Seborrhoeic keratosis


Fig. 5: Malignant melanoma

to rule out melanomas. These can be classified based on the presence or absence of proliferation of melanocytes as melanocytic and non melanocytic lesions.

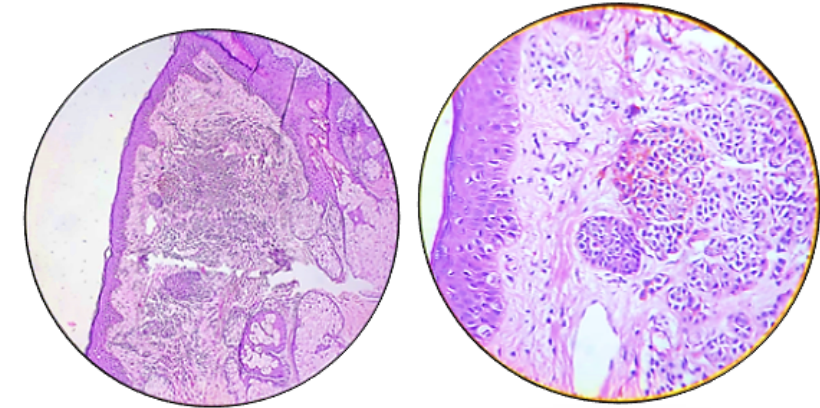

Fig. 6: Melanocytic naevi

\subsection{Melanocytic lesions}

Out of the 70 cases studied $22(31 \%)$ cases of melanocytic lesions consisting of 12 cases(17.1\%) Malignant melanomaand 10 cases $(14.2 \%)$ of Benign Nevi. Several studies in recent years have shown increasing incidence of cutaneous melanomas. "Panda et al"12, "Chang et al." 13 and "Mukhopadhyay et al", ${ }^{2}$ reported $82 \%$ and $78 \%$ of the cases to be of cutaneous origin. During our study period, there were no non cutaneous melanomas. However, among all melanocytic lesions cutaneous melanomas predominate with $17.1 \%$ of cases. Cutaneous malignant melanomas can occur denovo or in a pre existing nevus.

Cutaneous Melanomas are classified into superficial spreading, lentigo maligna melanoma, nodular melanoma and acral lentiginous melanoma. In our study we found 12 cases, out of which 3 cases were Nodular type, 4 cases were Acral lentiginous, 3 were NOS, 1 case of Nevoid melanoma 

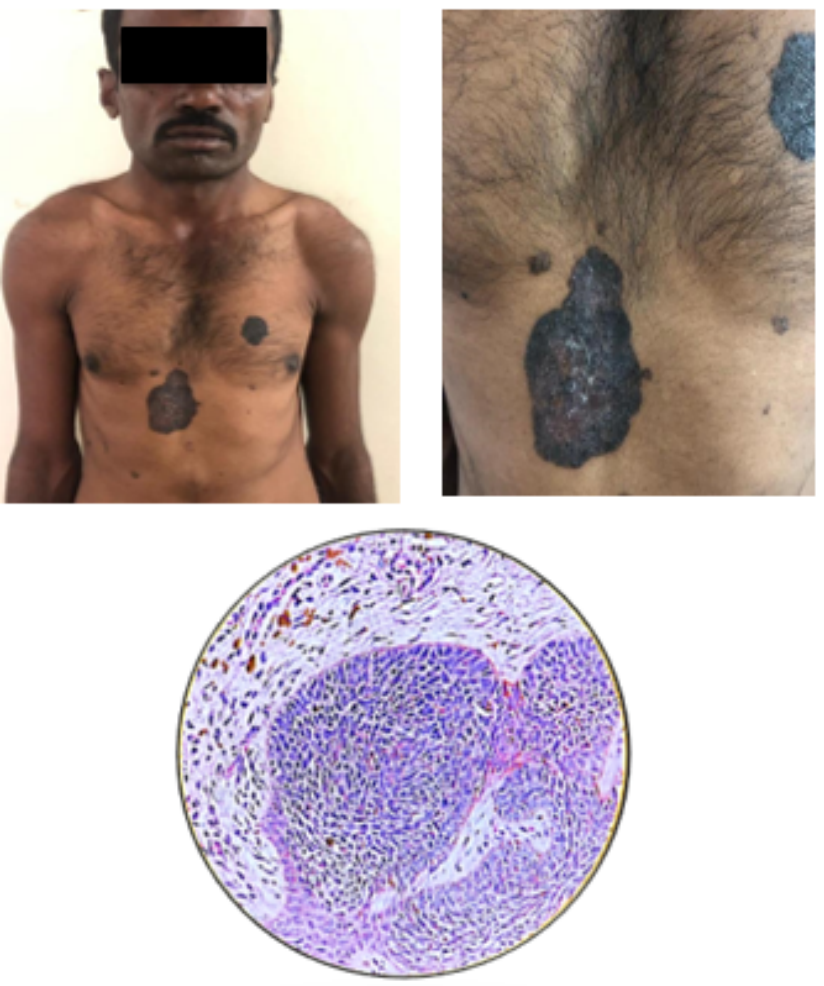

Fig. 7: Gorlin goltz syndrome
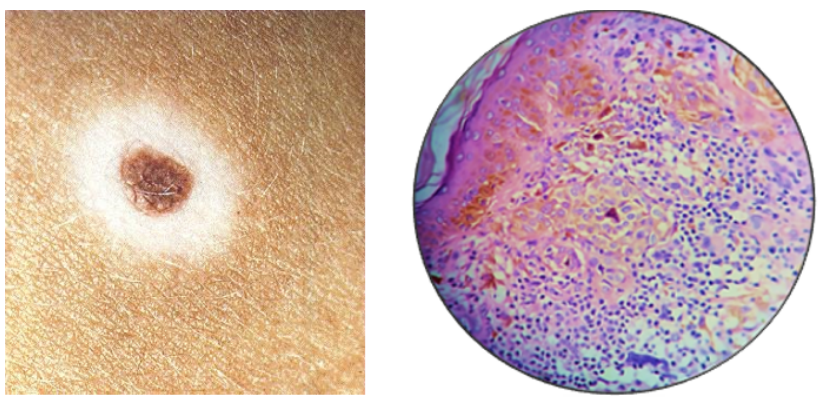

Fig. 8: Halo naevus

and 1 case of cutaneous myxoid melanoma were studied.

In contrast to our study, "Suvernekar et al." 14 and "Parvathi et al." 15 found Benign melanocytic naevi and pigmented $\mathrm{BCC}$ the most common type of lesions. BCC is the most common skin cancer but in the current study the number of cases diagnosed with Malignant melanoma are higher than BCC. This recent change in trend was also appreciated by "Panda et al." 16 in a study done in West Bengal. Many of the melanomas arise from a pre-existing nevus but the majority of the melanomas $(>50 \%)$ are Denovo.

Microscopically in nodular melanomas, asymmetry in size, shape, pigmentation of the nodules can be noted at a cytological level. Clarks grading was done and the majority of the lesions were Grade V. Similar studies done by "Shirazi et al." 17 showed most of the lesions in occuring in Clarks Grade III and IV.

Five Grades are recognized, and higher the grade, order is the prognosis. These grades are:

Grade 1: Melanoma confined to the epidermis (melanoma in situ)

Grade 2: Invasion into the papillary dermis

Grade 3: Invasion to the junction of the papillary and reticular dermis

Grade 4: Invasion into the reticular dermis

Grade 5: Invasion into the subcutaneous fat.

\subsection{Benign Melanocytic naevi}

Transformation of benign naevi to malignant melanoma is controversial but data suggests few melanoma have precursor lesions. Clinically these lesions can be similar and hence it is important to distinguish Benign naevi from Malignant melanoma.

\subsection{Non-Melanocytic lesions}

$48(69 \%)$ cases of non-melanocytic lesions consisting of Basal cell carcinoma- 8 cases( $11.4 \%$ ), Lichen planus- 30 cases $(42 \%)$ and Seborrheic keratosis- 10 cases $(14.3 \%)$ were noted. In overall distribution of pigmented lesions of the skin, lichen planus was the most common type of lesion seen in our study which was concordant to the results found in studies done by "Shushan et al." 5

These cases were distributed in the age group of 8 years to 92 years. Maximum number of cases were in the age group of 41-50 year old with few exceptions. Lichen planus was found to be commoner in younger patients.

The most common site of distribution of pigmented lesions of the skin were extremities more than head and neck and trunk. $70 \%$ of benign naevi cases were in head and neck region, $100 \%$ cases of malignant melanoma cases were in extremities, $70 \%$ of Seborrhoeic keratosis cases were in head and neck region. 100\% of the Basal cell carcinoma cases were in the face, head and neck area and lichen planus occuring most commonly in the extremities. These results were very close to the results found by "Parvathi et al." 15 in a study done in 2017.

\subsection{Basal cell carcinoma}

BCC is the most common type of skin cancer seen mostly in head and neck areas. In our study the biopsies showed stratified squamous epithelium with underlying nests of basaloid cells with palisading cells at the periphery. Tumour cells have hyperchromatic nuclei.

Surrounding stroma shows melanocytes with nests of melanophages. Solid pattern was the most common type of pattern seen compared to trabeculae and infiltrative. Out of 8 BCC cases, 7 were nodular BCC and 1 was associated with 
Gorlin goltz syndrome.

"Gorlin goltz syndrome is a multisystemic disease involving eye, skin, skeletal, neural and reproductive system with an autosomal dominant trait". ${ }^{18-20}$

"This syndrome has been termed with several names such as nevoid basal cell carcinoma syndrome, basal cell nevus syndrome, multiple basal cell carcinoma (BCC) syndrome, multiple basalioma syndrome, jaw cyst basal cell tumor skeletal anomalies syndrome, jaw cyst bifid rib basal cell nevus syndrome, nevoid basalioma, odontogenic keratocysts skeletal anomalies syndrome and fifth phacomatosis." 21,22 "In 1960, Robert James Gorlin and William Goltz discovered the classical triad (keratocysts in the jaws and bifid ribs, multiple basocellular epitheliomas) that established the diagnosis of this syndrome." 23

\subsection{Lichen planus}

It is a self limited eruption most commonly affecting young adults and have a female preponderance. Histomorphologically features like hyperkeratosis, orthokeratosis, acanthosis, hypergranulosis, band like infiltration and basal cell vacuolation were most commonly seen.

In the current study Max Joseph spaces and Civatte bodies were not so commonly seen but are specific along with band like lymphocytic infiltration in the papillary dermis and basal cell vacuolation.

Pigmentation in Lichen planus results from pigment incontinence as a consequence of basal cell damage. ICAMI(Intercellular Adhesion Molecule-1) expression is limited to basal cells in Lichen planus, resulting in leucocyte dependent damage to basal keratinocytes.

\subsection{Seborrheic keratosis}

Multiple large horn cysts filled with keratin and Proliferation of basaloid cells in irregular sheets enclosing the horn cysts were the most common and specific histological features of Seborrheic Keratosis. There are various histological types/variants of Seborrheic Keratosis. They are: Acanthotic type, Clonal type, Hyperkeratotic type, Adenoid/Reticulated type and Irritated type.

Melanin is present in the basal cell normally and pigmentation in Seborrheic keratosis is due to accentuation of basal cell proliferation.

\section{Conclusion}

Among the melanocytic lesions, our study revealed an increasing emergence of cutaneous melanomas. The predominance of cutaneous melanomas in our study among melanocytic lesions compels us to believe if there is an increasing trend of cutaneous melanomas in South India, which is considered rare so far. This study highlights a rare case of Gorlin Goltz syndrome in a young man. In our study the pigmented lesions are categorised into melanocytic and non melanocytic lesions for a better understanding. Thus, study appeals to emphasize on histomorphological study of pigmented lesions of skin as it continues to be the cornerstone in diagnosing cutaneous melanomas.

\section{Source of Funding}

None.

\section{Conflict of Interest}

None.

\section{References}

1. Dutta AK, Datta PK, Dhar S. IADVL textbook and atlas of dermatology. In: Valia RG, Valia AR, editors. Hyperpigmentary disorders. vol. 1. Mumbai: Bhalani; 2003. p. 760-98.

2. Mukhopadhyay S, Ghosh S, Siddhartha D, Mitra PK. A clinicopathological study of malignant melanoma with special reference to atypical presentation. Indian J Pathol Microbiol. 2008;51(4):485-8.

3. Elder DE, Elenitsas R, Murphy GF, Xu X. Benign Pigmented Lesions and Malignant Melanoma. In: and others, editor. Lever's Histopathology of the Skin. Lippincott Williams and Wilkins; 2009. p. 699-790.

4. Hussain MR. Melanocytic dysplastic naevi the middle ground between benign melanocytic naevi and cutaneous malignant melanomas: emerging clues. J Clin Pathol. 2005;58(5):453-6.

5. Jayker SS, Anantharaj J, Surhonne SP, Ramachandra R, Gurumurthy RY. Histopathological Spectrum of pigmented Lesions of Skin. J Evol Med Dent Sci. 2016;5(34):1913-6.

6. Tjarta A, Kanoko M, Ueda M, Hamzah M, Cipto H, Ichihashi M, et al. Rare case of melanoma studied for Its histopathological features in Indonesia. Med J Indonesia. 2000;9:93-9.

7. Vishnoi JR, Kumar V, Kori CG, Gupta S, Misra S, Akhtar N. Primary malignant melanoma of oral cavity: A tertiary care center experience. Natl J Maxillofac Surg. 2015;6(2):167-71.

8. Thapa S, Ghosh A, Ghartimagar D, Prasad T, Narasimhan R, Talwar OP. Clinico-pathological Study of Malignant Melanoma in A Tertiary Care Centre. J Nepal Med Assoc. 2017;56(205):132-6.

9. Vayer A, Lefor AT. Cutaneous melanoma in African-Americans. South Med J. 1993;86(2):181-2.

10. Chopra A, Walia R, Gupta S, Sethi PS, Bagga HK. Nodular malignant melanoma - Secondary to carcinoma rectum. Indian J Dermatol Venereol Leprol. 1997;63:327-9.

11. Khandpur S, Reddy BS. Acral lentiginous melanoma. Indian J Dermatol Venereol Leprol. 2000;66:37-8.

12. Besra K, Panda S, Dash S, Samantaray S, Pathy PC, Rout N. Clinicopathological study of malignant melanoma in a regional cancer center. Indian J Cancer. 2018;55(3):292-6.

13. Chang JW. Cutaneous melanoma: Taiwan experience and literature review. Chang Gung Med J. 2010;33:602-12.

14. Suvernakar SV, , Harwani RS, Deshpande SA. Clinicopathological Study of Pigmented Skin Lesions. IOSR J Dent Med Sci. 2014;13(5):70-3.

15. Parvathi M, Balaji C, Lekha GD, Kumar SS. Bhagya Lakshmi- A clinico-pathological study of pigmented cutaneous lesions: a one-year prospective study in a tertiary care hospital. Int J Res Med Sci. 2017;5(12):5316-21

16. Panda S. Nonmelanoma skin cancer in India: Current scenario. Indian J Dermatol. 2010;55:373-8.

17. Shirazi N, Jindal R, Singh S, Harsh M, Ahmad S. Pigmented Premalignant and Malignant Lesions of Skin with Special Reference to Atypical Presentations . J Clin Diagn Res. 2015;9:10-2. 
18. Casaroto AR, Loures DCNR, Moreschi E, Veltrini VC, Trento CL, Gottardo VD. Early diagnosis of Gorlin-Goltz syndrome: case report.

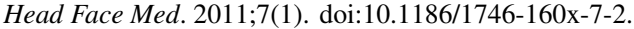

19. Yordanova I, Gospodinov D, Kirov V, Pavlova V, Radoslavova G. A familial case of gorlin-goltz syndrome. J IMAB. 2007;13:59-63.

20. Manfredi M, Vescovi P, Bonanini M, Porter S. Nevoid basal cell carcinoma syndrome: a review of the literature. Int J Oral Maxillofac Surg. 2004;33(2):117-24.

21. Acocella A, Sacco R, Bertolai R, Sacco N. Genetic and clinicopathologic aspects of Gorlin-Goltz syndrome (NBCCS): Presentation of two case reports and literature review. Minerva Stomatol. 2009;58:43-53.

22. Mamatha GP, Reddy S, Rao BB, Mujib A. Gorlin syndrome. A case report. Indian J Dent Res. 2001;12:248-52.

23. Gorlin RJ, Goltz RW. Multiple Nevoid Basal-Cell Epithelioma, Jaw Cysts and Bifid Rib. N Engl J Med. 1960;262(18):908-12.

\section{Author biography}

Ishant Anand, Resident

Sandhya Ilanthodi, Associate Professor

Girish P N, Dermatologist

Muktha R Pai, HOD

Cite this article: Anand I, Ilanthodi S, Girish P N, Pai MR. A

histo-pathological study with an emphasis on stratification of pigmented lesions of the skin. Indian J Pathol Oncol 2020;7(4):643-649. 